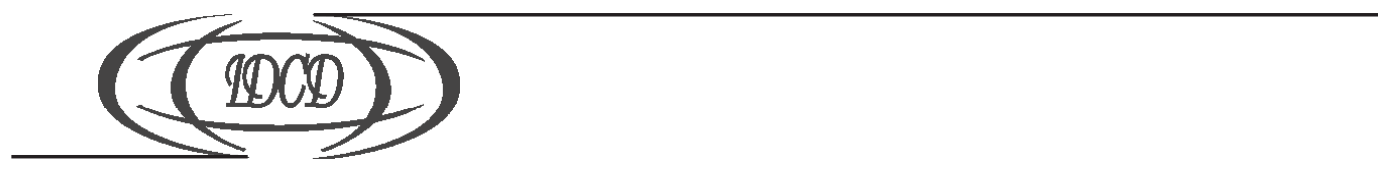

УДК 331.5

\title{
Е.А. ГРИШНОВА,
}

д-р экон. наук, проф.,

Киевский национальный университет им. Тараса Шевченко

E-mail: grishnova@ukr.net

\section{Н.А. АЗЬМУК,}

канд. экон. наук, зам. дир.,

Черкасский государственный бизнес - колледж

E-mail: azmukna@gmail.com

\section{РАЗВИТИЕ ЧЕЛОВЕЧЕСКОГО КАПИТАЛА И ТРАНСФОРМАЦИЯ ФОРМ ЗАНЯТОСТИ: ВЗАИМОВЛИЯНИЕ И ВЗАИМООБУСЛОВЛЕННОСТЬ}

В статье обоснованы основные тенденции использования человеческого капитала на современном глобальном рынке труда. Исследованы и систематизированы современные условия реализации человеческого капитала, обоснована взаимосвязь и взаимообусловленность развития человеческого капитала и трансформации форм занятости.

Ключевые слова: человеческий капитал, инновационные формы человеческого капитала, нестандартные формы занятости, глобализация, информационно-компьютерные технологии.

Постановка проблемы. Определяющими признаками современного социально-экономического развития являются интеллектуализация и глобализация, характер и скорость которых видоизменяют модель мира и место в ней отдельных государств, включая и Украину. Один из важнейших глобальных процессов - интеллектуальный передел мира: соревнование между странами за обладание последним пока не распределенным мировым ресурсом - человеческим интеллектом, а именно за привлечение носителей современных знаний и создателей новой техники, технологии, культуры. Человеческий капитал становится не просто определяющим фактором конкурентоспособности, но и доминирующей формой общественного богатства, основой интеллектуального и социального капитала как условия не только экономического, но и цивилизационного прогресса в целом. На фоне глобализации экономики развиваются принципиально иные экономические связи и производственные отношения, тесно связанные с изменениями в социально-трудовых отношениях, в частности в формах занятости. 
С одной стороны, человеческий капитал развивается, и его значение всё возрастает. Более развитый и более ценный человеческий капитал имеет право расчитывать на более удобные формы его реализации (да и по соображениям экономической целесообразности надо искать оптимальные формы его рационального использования). В высококонкурентной глобализированной экономике от предприятий требуется очень большая гибкость, мобильность, адаптивность. Этого невозможно достичь, применяя только традиционные виды и формы занятости, необходима их трансформация. Таким образом формируется и нарастает спрос и предложение робочих мест с гибкими, нестандартними формами занятости.

С другой стороны, новые формы занятости выдвигают требования и создают условия для дальнейшего развития человеческого капитала, причём как специфических профессиональных качеств, так и ещё в большей степени - общих, включающих не только широкие знания и умения, но и сильные личностные характеристики.

Научное исследование этих взаимосвязанных процессов важно для поиска и обоснования рациональных путей их развития.

Анализ последних исследований и публикаций. Вопросами современных системных трансформаций, которые прежде всего включают изменения в человеческом, социальном, интеллектуальном капитале и обусловливают особенности их развития и использования в сфере занятости, занимаются отечественные и зарубежные ученые $[3 ; 4 ; 6]$. Вместе с тем вопросы взаимовлияния и взаимообусловленности интеллектуализации труда, развития человеческого капитала и трансформации форм занятости остаются недостаточно изученными и требуют углубленного исследования.

Цель исследования заключается в изучении и систематизации современных условий и особенностей развития человеческого капитала, обосновании взаимовлияния и взаимосвязи развития человеческого капитала и трансформации форм занятости.

Основные результаты исследования. Отметим сразу, что соотношение человеческого, интеллектуального и социального капиталов на макроуровне является очень сложным и довольно трудно поддается схематической формализации. По нашим исследованиям, на макроуровне интеллектуальный капитал и социальный капитал, хотя и являются объектами самостоятельного анализа, однако, наряду с другим, характеризуют национальный (общественный) человеческий капитал. Интеллектуальный капитал, а прежде всего - именно та основная его часть, которая воплощена в человеческих умственных способностях, знаниях и компетенциях (мы его называем когнитивным капиталом), является важнейшим стратегическим ресурсом современной экономики и главным источником накопления национального богатства. Знания все больше становятся доминирующим фактором повышения конкурентоспособности как предприятий, так и страны в целом. Интеллектуальный труд обеспечивает внедрение новых технологий, увеличение объемов ВВП и улучшение благосостояния граждан.

Инвестиции в интеллектуальный капитал обусловливают рост производительности труда, в частности , в странах ЕС и США на $20 \%-34 \%$, о чем свидетельствуют данные отчета ОЭСР «Поддержка инвестиций в интеллектуальный капитал, развитие и инновации» [1].

Следовательно, предприятия и правительства развитых стран изменяют структуру инвестиций, увеличивая капиталовложения в нематериальные активы, развитие персонала, совершенствование организационной структуры и бизнес-процессов. Постепенно происходит процесс замещения физического капитала на интеллекту- 
альный, ведь именно инвестиции в интеллектуальный капитал наиболее прибыльные и быстрее дают и экономический, и социальный эффект.

Структурно интелектуальный капитал традиционно определяется как комбинация человеческого, организационного и капитала отношений [2]. На макроуровне интеллектуальный капитал включает знания, способности, опыт занятого населения, а также национальные условия, в которых реализуется человеский капитал: культуру, нормы, эффективность государственных структур, системы образования и здравоохранения, научные структуры, а также вовлеченность страны в международные процессы, привлекательность для инвестиций и совместных проектов. Наиболее важной составляющей интеллектуального капитала является именно человеческий капитал, поскольку, кроме самостоятельной ценности, он также формирует и две другие составляющие: организационную и отношенческую.

Современные предприятия повышают свою конкурентоспособность за счет приобретения и использования уникальных знаний, опыта, способностей работников и их возможностей к продуцированию новых идей. Вместе с тем, по оценкам Билла Джоя, известного ученого сферы ИТ-технологий, около $20 \%$ технических знаний ежегодно теряют свою коммерческую ценность [3]. Это, в свою очередь, приводит к снижению рыночной стоимости патентов, систем, баз данных и других нематериальных активов компании, а также требует постоянного обновления знаний и компетенций персонала. Однако именно человеческий капитал обладает способностью к самостоятельному обновлению и улучшению имеющихся ценных характеристик и усилению возможностей к продуцированию инноваций.

По нашему определению, человеческий капитал - это сформированный и развитый в результате инвестиций и накопленный человеком определенный запас здоровья, знаний, навыков, способностей, мотиваций, который целенаправленно используется в определенной сфере экономической деятельности, способствует повышению производительности труда и, благодаря этому, влияет на рост дохода своего владельца, прибыли предприятия и национального дохода [4].

Качество человеческого капитала разных стран и факторы его формирования определены в отчете Всемирного экономического форума «Человеческий капитал в 2013 г.» [5]. В отчете проанализированы условия развития человеческого капитала 122 стран мира по 51 показателю, которые сгруппированы по четырем аспектам: образование; здравоохранение и благосостояние; рабочая сила и занятость; благоприятность внешней среды. К странам - лидерам по уровню развития человеческого капитала в порядке убывания относятся: Швейцария, Финляндия, Сингапур, Голландия, Швеция, Германия, Норвегия, Великобритания, Дания, Канада. То есть лучшие показатели по уровню развития человеческого капитала получили страны с высоким уровнем ВВП на душу населения (выше 12000 долл. США). Важно, что при этом первые строчки заняли европейские страны, в которых сформирована социально ориентированная экономика. К странам- аутсайдерам относятся бедные государства с низким уровнем ВВП на душу населения, среди которых последние места от самого низкого в восходящем порядке заняли: Йемен, Мавритания, Гвинея, Буркина Фасо, Мали, Мозамбик.

Зависимость между уровнем развития человеческого капитала и уровнем ВВП характерна и для бывших советских республик, которые имеют такие значения в общем рейтинге: Казахстан занимает 45-е место, Россия - 51, Украина - 63. Показатели развития человеческого капитала в странах, близких по социально-экономическому развитию к Украине, приведены в табл. 1 [5]. 
Таблица 1.Показатели уровня развития человеческого капитала (позиция в рейтинге 122 стран).

\begin{tabular}{|l|c|c|c|c|c|}
\hline Страны & $\begin{array}{c}\text { Общий рей- } \\
\text { тинг }\end{array}$ & Образование & $\begin{array}{c}\text { Здравоохра- } \\
\text { нение }\end{array}$ & $\begin{array}{c}\text { Рынок труда и } \\
\text { занятость }\end{array}$ & $\begin{array}{c}\text { Благоприят- } \\
\text { ность внешней } \\
\text { среды }\end{array}$ \\
\hline Польща & 49 & 42 & 47 & 63 & 57 \\
\hline Россия & 51 & 41 & 62 & 66 & 63 \\
\hline Венгрия & 54 & 33 & 73 & 77 & 62 \\
\hline Болгария & 56 & 46 & 33 & 100 & 74 \\
\hline Украина & 63 & 45 & 55 & 67 & 96 \\
\hline Румыния & 69 & 57 & 61 & 85 & 83 \\
\hline
\end{tabular}

Источник: [5]

Результаты анализа свидетельствуют о наличии тесной связи между уровнем экономического развития страны и уровнем развития человеческого капитала. Это объясняется не столько тем, что развитые страны имеют большие возможности инвестировать в образование, здравоохранение, улучшение условий труда, а прежде всего - тем, что качественный человеческий капитал обеспечивает лучший экономический и социальный результат. Также большое значение для развития человеческого капитала имеет благоприятность внешней среды, которую создало государство для своих граждан.

Таблица 2. Характеристики человеческого капитала в традиционной и современной экономике

\begin{tabular}{|l|l|l|}
\hline \multicolumn{1}{|c|}{ Характеристики } & \multicolumn{1}{|c|}{ Традиционная экономика } & \multicolumn{1}{|c|}{ Современная экономика } \\
\hline Собственник & $\begin{array}{l}\text { Работник - носитель интеллектуальных, физических, психологических } \\
\text { способностей }\end{array}$ & $\begin{array}{l}\text { Работодатель или сам работник, } \\
\text { если это самозанятое лицо }\end{array}$ \\
\hline Потребитель & Работодатель & $\begin{array}{l}\text { Работодатель, но все чаще - сам } \\
\text { работник }\end{array}$ \\
\hline Инвестор & Чаще всего - работодатель & $\begin{array}{l}\text { Уменьшение доли специфического } \\
\text { капитала с одновременным уве- } \\
\text { личением общих знаний и навы- } \\
\text { ков, которые имеют ценность для } \\
\text { многих работодателей }\end{array}$ \\
\hline $\begin{array}{l}\text { Структура челове- } \\
\text { ческого капитала } \\
\text { чебщий и специфи- } \\
\text { ческий })\end{array}$ & $\begin{array}{l}\text { Значительная часть специфиче человеческого капитала, } \\
\text { который имеет ценность только } \\
\text { для одного конкретного работо- } \\
\text { дателя }\end{array}$ & $\begin{array}{l}\text { Увеличивается влияние неденеж- } \\
\text { ных факторов: признание успеха, } \\
\text { возможности для саморазвития, } \\
\text { дополнительное свободное время, } \\
\text { гибкий график работы и т.п. }\end{array}$ \\
\hline $\begin{array}{l}\text { Мотивы экономи- } \\
\text { ческого поведения }\end{array}$ & $\begin{array}{l}\text { Существенно преобладают мате- } \\
\text { риальные мотивы }\end{array}$ & $\begin{array}{l}\text { Высокая профессиональная и тер- } \\
\text { риториальная мобильность. Увели- } \\
\text { чивается доля временно занятых }\end{array}$ \\
\hline $\begin{array}{l}\text { Уровень мобильнос- } \\
\text { ти человеческого } \\
\text { капитала }\end{array}$ & $\begin{array}{l}\text { Незначительный, работодатель } \\
\text { вимулирует стабильность, при- } \\
\text { веженность работника к пред- } \\
\text { приятию }\end{array}$ & Сфера услуг \\
\hline $\begin{array}{l}\text { Основная сфера за- } \\
\text { нятости }\end{array}$ & Промышленность & \\
\hline
\end{tabular}


Совокупный человеческий капитал состоит из отдельных образованных, способных и талантливых людей с ярко выраженной индивидуальностью. Он всегда был самым сложным фактором производства и управления, но в современных условиях эта сложность многократно возрастает. Авторское обобщение основных характерных признаков человеческого капитала в традиционной и современной экономике показано в табл.2.

Расмотренные в табл. 2 характерные признаки дают возможность сформировать несколько принципиальных положений относительно особенностей использования человеческого капитала на современном рынке труда, подтверждающих взаимообусловленность его развития и трансформации форм занятости.

Bo-nервых, человеческий капитал является неотъемлемым от своего носителя - человека и принадлежит ему вместе со всеми врожденными и приобретенными свойствами. Каждый носитель знаний, умений, опыта имеет свой уникальный комплекс характеристик и свойств, которые сформированы под влиянием определенных факторов. А главное - человеческий капитал способен развиваться и накапливаться. При этом инвестором его развития может выступать как работодатель , так и сам работник. Работодатель может инвестировать в человеческий капитал прямо и опосредованно через оплату обучения, повышение квалификации, а также путем предоставления возможности приобретать опыт в компании, общаться с коллегами и т.д. Однако главным инвестором является сам работник, поскольку человек всегда инвестирует свои силы и время в наращивание своего человеческого капитала, а также, решение о целесообразности и интенсивности приобретения новых знаний, опыта, саморазвития в той или иной сфере остается за ним. При этом чем выше профессиональный, интеллектуальный уровень работника, больше его возможности к продуцированию инноваций, тем выше уровень его конкурентоспособности. Следует подчеркнуть, что в современной экономике появляются инновационные формы человеческого капитала.

Инновационные формы человеческого капитала повышают способность работника приспосабливаться к изменениям в технологической и экономической среде, что делает его более гибким и мобильным независимо от того, где осуществляется трудовая деятельность [6]. В наше динамичное время растет спрос на профессионалов, которые, кроме глубоких знаний специальности, компьютерной грамотности, владения иностранными языками, имеют также навыки использования электронных сетей и виртуального сотрудничества, креативное мышление, профессиональные знания в смежных сферах, профессиональную ответственность, адаптивность и мобильность. Характерно, что определенные инновационные формы человеческого капитала очень быстро распространяются и становятся уже не конкурентным преимуществом, а обязательным требованием к современному работнику.

Bо-вторых, основным сектором использования человеческого капитала в современной экономике является сфера услуг. По экспертным оценкам, доля занятых в непроизводственной сфере в развитых странах составляет 60-80 \% общей занятости. Сфера услуг очень динамична и активна в использовании информационных технологий, она по своей специфике не требует значительных материальных затрат и имеет значительный потенциал для наращивания интеллектуального капитала, прежде всего человеческого. Именно в этой сфере особое значение приобретает социальный капитал как практика эффективного взаимодействия между производителем и потребителем услуг. Появились новые интеллектуальные компании, которые 
имеют незначительные материальные активы, что позволяет существенно снизить затраты на их содержание и направить инвестиции в интеллектуальный капитал. Кроме того, активное развитие информационно-компьютерных технологий обусловливает необходимость прежде всего этого сектора экономики в инновационных формах человеческого капитала.

$B$-третьих, характерной для современных экономических систем является трансформация структуры человеческого капитала - снижение доли специфического человеческого капитала. Своеобразным показателем увеличения уровня общего человеческого капитала может быть возрастание доли занятых, работающих «в проектах», по договорам с ограниченным сроком действия.

Значение этого показателя в среднем по Европе постепенно возрастает от 8,2\% в 1980 г. до 14,1 \% в 2012 г. Самые высокие показатели в 2012 г. имеют такие страны: Польша (26,9 \%), Испания (23,6 \%), Португалия (20,7 \%), Нидерланды $(19,5 \%)$, Словения $(17,1 \%)$, Швеция $(16,4 \%)$, Финляндия $(15,7 \%)$, Франция $(15,2 \%)$ [7]. При этом существует тесная связь между возрастом работника и временным статусом его работы: с одной стороны, чем моложе работник, тем труднее ему найти постоянную работу, которая бы его устраивала, а с другой - по специфике молодежных потребностей такие работники более склонны к работе по договорам с ограниченным сроком действия.

В частности, в среднем по Европе в 2012 г. в возрастной группе 15-24 года работает по временным контрактам 39,2\% от общего количества занятых , в возрастной группе 25-54 лет $-11,7 \%$, в группе 55-64 г. - 7,3 \%. Подчеркнем, что для всех возрастных групп в период с 1980 до 2012 г. характерен рост доли занятых по договорам с ограниченным сроком действия на $79 \%-100 \%$, а наибольшие темпы роста приходятся на среднюю возрастную категорию 25-54 лет [7].

Таким образом, одной из важных тенденций современного рынка труда является увеличение количества временных работников. Основными факторами, которые обусловливают спрос предприятий на временных сотрудников, являются: снижение затрат, сезонные колебания спроса, возможность замещения сотрудников, быстрая адаптация предприятия к экономическим циклам, отсутствие обязательств по гарантии занятости.

$B$-четвертых, спрос среди работодателей на временный квалифицированный труд обусловливает появление и активное развитие посреднических фирм, специализирующихся на подборе и предоставлении персонала на условиях лизинга и аутстаффинга. Отличие лизинга персонала от аутстаффинга заключается в том, что при аутстаффинге происходит выведение персонала из штата предприятия, хотя работники продолжают выполнять свои трудовые функции для него, а фирма-посредник берет на себя функции выплаты заработной платы, уплаты налогов и т.п. При лизинге фирма-посредник предоставляет предприятию в аренду персонал соответствующей квалификации для выполнения определенного объема работ на временной основе.

Одним из лидеров в сфере предоставления таких услуг является кадровая корпорация Manpower, которая имеет 3500 офисов в 80 странах мира, в т.ч. и в Украине. Общее количество трудоустроенных данной компанией составляет более 4 млн человек, из них штатных работников около 30000 человек, остальные - по контрактам [8].

$B$-nятых, для современного рынка труда характерно появление новых форм гибкой занятости. Новой формой временной занятости, позволяющей существенно снижать 
затраты на персонал, является краудсорсинг. Краудсорсинг (англ. crowd - «толпа» и sourcing - «использование ресурсов») - передача тех или иных производственных функций неопределенному кругу лиц на основании публичной оферты без заключения трудового договора. То есть мобилизация человеческих ресурсов, как правило, на конкурсной основе посредством использования информационных технологий, а именно глобальных информационных платформ для решения необходимых задач.

Крупнейшей в мире платформой краудсорсинга является Witmart, которая объединила 9 млн пользователей, предоставляющих услуги по графическому дизайну, переводу, веб -дизайну, копирайтингу, продажам, аналитике, маркетингу и т.д. [9]. Платформа Topcoder - это сообщество, насчитывающее более 615 тыс. разработчиков ПО, аналитиков, дизайнеров. Среди компаний, которые пользовались возможностями названной платформы - Гарвардская школа бизнеса, AMD, DAPRA, Alcatel, ESPN, AOL, ING, UBS, Яндекс, Google, Yahoo, Microsoft и др.[10].

$B$-шестых, экономическое поведение работника зависит не только от экономических факторов, таких как: уровень заработной платы, социальное обеспечение и т.д. Значительное влияние на решение индивида имеют нематериальные факторы: карьерный рост, возможности для самореализации, признание его достижений, гибкий график работы, большая свобода в использовании свободного времени. При этом работник, достигший успеха в своей профессиональной деятельности, имеет широкие возможности выбора работодателя и нередко со временем отдаёт предпочтение «работе на себя».

Доля самозанятых лиц в 2010 г. варьировала от 7\% в США до 35,5 \% в Греции, 34,3 \% в Мексике, 39\% в Турции. Как правило, более высокий уровень самозанятости характерен для стран с низким уровнем дохода, при этом исключением являются такие страны, как: Италия (25,5 \%), Португалия (22,8 \%), Ирландия (32,3 \%) [11]. Отметим, что самозанятость дает значительные возможности для самореализации, достижения успеха в своей сфере, поскольку такой человек работает сам на себя, что обусловливает высокий уровень мотивированности. Одновременно массовая самозанятость на простых, неквалифицированных работах свидетельствует скорее о недостатке производительных рабочих мест в экономике, чем о сознательном добровольном выборе работников.

$B$-седьмых активное развитие информационно-компьютерных технологий и доступность Интернета приводит к перемещению определенного количества рабочих мест за производственные и офисные помещения и к широкому использованию дистанционной формы занятости. Это, в свою очередь, обусловливает появление новых форм организации рабочего места, в том числе все большую популярность приобретает коворкинг .

Коворкинг (англ. co-working - «совместно работать») - это новая форма организации работы, при которой самозанятые лица, как правило фрилансеры, используют для своей профессиональной деятельности общее офисное пространство, оставаясь независимыми и свободными, но не испытывая при этом недостатка в общении. Идея возникла в США в 2005 году: молодой программист Брэд Ньюберг решил совместить традиционный офис со свободой и независимостью фриланса.

Таким образом, коворкинг - это наем рабочего места с готовой инфраструктурой и услугами: секретаря, охраны, уборки и т.п., а главное - это возможность работать в творческой среде, находиться в сообществе единомышленников, творческих профессионалов. 
Примером эффективного и одновременно бесплатного коворкинг- центра является Hacker Dojo (Силиконовая долина), который помимо стандартного оборудования имеет еще и мастерскую, оснащенную различными приборами - от паяльников и микроскопов до 3D-принтера и элементов робототехники. Кроме того, в рамках центра проводятся встречи между разработчиками инноваций и потенциальными инвесторами [12].

Такая форма организации рабочего места используется во всем мире, в т.ч. и в Украине. Первые коворкинг- центры в нашей стране появились в 2009 г., что прежде всего связано с экономическим кризисом, высвобождением значительного количества офисных площадей и невозможностью предпринимателей и дальше платить большую арендную плату. Сегодня коворкинг-центры работают в крупных городах: Киеве, Харькове, Одессе, Львове, Днепропетровске и др. Такая форма организации рабочего места пользуется наибольшим спросом среди электронных фрилансеров и стартапов.

Электронный фрилансер - это независимый профессионал, который сам ищет себе проекты, может одновременно работать на несколько фирм, при этом работа выполняется дистанционно. Поиск заказчика, связь с ним, передача выполненной работы, расчеты и т.п. осуществляется с помощью информационно-компьютерных технологий.

По данным elance.com, в одной из крупнейших онлайновых платформ в мире численность зарегистрированных на ней фрилансеров по состоянию на начало 2014 года составляет 3,5 млн человек. Согласно статистике данного сайта, украинские фрилансеры за 5 лет заработали с его помощью около 36,5 млн дол. США. А в 2013 г. украинские фрилансеры заняли третье место по количеству и объемам выполненных заказов, совсем немного уступая США и Индии [13].

Cmapman - это бизнес, основанный одним лицом или группой лиц, как правило официально не зарегистрированных, которые создают новый бизнес на основе разработки инновационного продукта или технологии. Инновации, на основе которых строят свой бизнес стартапы, могут быть как глобальными, так и локальными. Примерами стартапов могут быть: Wikipedia - свободная общедоступная мультиязычная универсальная интернет-энциклопедия, Dialoggy - единственная открытая книга отзывов и предложений о работе различных компаний, Flick - сервис сохранения фотографий, Dropbox - система обмена и обработки файлов, 5crm - CRM-система.

Выводы. Таким образом, для современных экономических систем характерна интеллектуализация производства, активное развитие сферы услуг и широкое использование информационно-компьютерных технологий, что порождает тенденцию к изменению соотношения между физическим и человеческим капиталом в пользу последнего. Это обусловливает появление инновационных форм человеческого капитала, динамично развивающихся и быстро распространяющихся. Высокий профессионализм, оставаясь основой и глубинной сутью человеческого капитала, в современных условиях требует «инновационного оформления» в виде компьютерной грамотности, знания иностранных языков, умения работать в сетях, широких компетенций, в том числе в смежных сферах, профессиональной ответственности, адаптивности, мобильности. Особенности человеческого капитала, прежде всего - способность к инновациям, обуславливают его уникальность, а следовательно, и предоставляют возможность выбирать работодателя, форму занятости, условия работы, форму вознаграждения. Уникальность свойств личности повышает ее кон- 
курентоспособность на рынке труда. Это дает возможность талантливому работнику дистанциироваться от работодателя и работать независимо.

Инновационные формы человеческого капитала требуют инновационных форм его использования, поэтому ситуация на современном рынке труда характеризуется двумя взаимосвязанными тенденциями: во-первых, изменения в содержании труда обусловили спрос среди работников на нестандартную занятость, поскольку такая форма дает больше свободы творчества и возможностей для самореализации. С другой стороны, современные предприятия активно ищут возможности для гибкости и мобильности, и поэтому заинтересованы в использовании гибких форм занятости, прежде всего дистанционной и временной.

Прямая взаимосвязь между развитием человеческого капитала и трансформацией форм занятости проявляется в том, что реализуется человеческий капитал на рынке труда через те или иные формы занятости, и эти формы тем сложнее и разнообразнее, чем уникальнее человеческий капитал. Обратная связь проявляется в том, что трансформация форм занятости предоставляет дополнительные возможности и выдвигает новые требования для накопления человеческого капитала, в результате чего происходит его развитие. Обоснованные в статье принципиальные положения относительно особенностей использования человеческого капитала на современном рынке труда подтверждают взаимообусловленность его развития и трансформации форм занятости.

Следует отметить, что современные изменения в сфере занятости, безусловно, способствуют наращиванию человеческого капитала, повышая спрос и создавая возможности интеллектуального развития и роста мобильности работников. Вместе с тем нельзя однозначно утверждать об исключительно положительном влиянии современных изменений в социально-трудовых отношениях на развитие человеческого капитала. Наростающая индивидуализация, ненормированная, неравномерная занятость, снижение уровня социальной защиты, неуверенность в будущем - это далеко не все минусы нестандартних форм занятости. Другие (кроме интеллектуальной) составляющие человеческого капитала, прежде всего здоровье и социальные связи, также подвергаются большему риску при нестандартных формах занятости. Соответственно, такая ситуация требует социальных инноваций в виде вариантов решения этих проблем, что требует дальнейших научных исследований.

\section{ЛИТЕРАТУРА}

1. Supporting Investment in Knowledge Capital, Growth and Innovation: OECD 2013 - [Electronic resource]. URL: http://www.oecd-ilibrary.org/industry-and-services/supporting-investment-in-knowledge-capital-growth-and-innovation_9789264193307-en (дата обращения:14.01.2014)

2. Reporting intellectual capital to augment Research, Development and Innovation in SMEs. - Report to the Commission of the High Level Expert Group on RICARDIS. Luxembourg: Office for Official Publications of the European Communities. 2006. - 164 p.

3. Нордстрем К., Риддерстрале Й. Караоке-капитализм. Менеджмент для человечества. Пер. с англ.[В. Мишучкова]; Стокгольмская школа экономики. - 2 изд. - М.: Манн, Иванов и Фербер, 2008. - $336 \mathrm{c}$.

4. Економіка праці та соціально-трудові відносини: підручник / [А.М. Колот, О.А. Грішнова, О.О. Герасименко та ін.]; за наук ред. А.М. Колота. - К., КНЕУ, 2009. - 711 с.

5. The Human Capital Report 2013 - [Electronic resource]. URL: http://reports.weforum.org/humancapital-index-2013/\#= (дата обращения: 18.01.2014). 
6. Капелюшников Р.И., Лукьянова А.Л. Трансформация человеческого капитала в российском обществе. /Р. И. Капелюшников,. - Москва: Фонд «Либеральная миссия», 2010. - [Электронный pecypc]. URL: http://www.liberal.ru/upload/files/Kapelushkin_Final_Web\%20(2).pdf (дата обращения 15.01.2014).

7. Temporary employment: OECD. [Electronic resource]. URL: http://stats.oecd.org/Index.aspx?DatasetCode=TEMP_I (дата обращения 02.03.2014).

8. Manpower employment Outlook Survey Global Q1/14. - [Electronic resource]. URL: http://www. manpowergroup.com/ (дата обращения 22.12.2013).

9. Witmart. - [Electronic resource]. URL: http://www.witmart.com/ (дата обращения 01.03.2014).

10. Topcoder. - [Electronic resource]. URL: www.topcoder.com/ (дата обращения 01.03.2014).

11. Self-employment: OECD Factbook. - [Electronic resource]. URL: http://www.oecd-ilibrary.org/sites/factbook-2011-en/07/01/04/index.html?itemId=/content/chapter/factbook-2011-61-en (дата обращения 25.01.2014).

12. Hacker Dojo - [Electronic resource]. URL: http://www.hackerdojo.com/ (дата обращения 27.12.2013).

13. Global Online Employment Report - Q3 2012: Elance. - [Electronic resource]. URL: https://www. elance.com/q/online-employment-report (дата обращения 27.02.2014).

\section{REFERENCES}

1. Supporting Investment in Knowledge Capital, Growth and Innovation: OECD 2013. (2014). Retrieved from http://www.oecd-ilibrary.org/industry-and-services/supporting-investment-in-knowledge-capitalgrowth-and-innovation_9789264193307-en [in English].

2. Reporting intellectual capital to augment Research, Development and Innovation in SMEs. Report to the Commission of the High Level Expert Group on RICARDIS. (2006). Luxembourg: Office for Official Publications of the European Communities [in English].

3. Nordstrem, K., Ridderstrale, J. (2008). Karaoke-kapitalizm. Menedzhment dlja chelovechestva. [Karaoke Capitalism. Management for mankind]. Stokgol'mskaja shkola jekonomiki. (2 izd.) M.: Mann, Ivanov i Ferber [in Russian].

4. Kolot, A.M., Grishnova, O.A., Gerasymenko, O.A. et al. (2009). Ekonomika praci ta social'no-trudovi vidnosyny: pidruchnyk [Labor Economics and social and labor relations: tutorial] K. KNEU [in Ukrainian].

5. The Human Capital Report 2013. (2014). Retrieved from http://reports.weforum.org/human-capitalindex-2013/\#= [in English].

6. Kapeljushnikov, R.I., Luk'janova, A.L. (2010). Transformacija chelovecheskogo kapitala v rossijskom obshhestve [Transformation of human capital in the Russian society]. Retrieved from http://www.liberal. ru/upload/files/Kapelushkin_Final_Web\%20(2).pdf [in Russian].

7. Temporary employment: OECD (2014). Retrieved from http://stats.oecd.org/Index.aspx? DatasetCode=TEMP_I [in English].

8. Manpower employment Outlook Survey Global Q1/14. (2013). Retrieved from http://www.manpowergroup.com/ [in English].

9. Site Witmart. Retrieved from http://www.witmart.com [in English].

10. Site Topcoder. Retrieved from www.topcoder.com [in English].

11. Self-employment: OECD Factbook. Retrieved from http://www.oecd-ilibrary.org/sites/factbook-2011en/07/01/04/index.html?itemId=/content/chapter/factbook-2011-61-en [in English].

12. Site Hacker Dojo. Retrieved from http://www.hackerdojo.com [in English].

13. Global Online Employment Report. (2012). Retrieved from https://www.elance.com/q/online-employment-report [in English].

Стаття надійшла до редакції журналу 27.01.2014 


\section{О.А. Грішнова,}

д-р екон. наук, проф., Київський національний університет ім. Тараса Шевченка

Україна, 01601, м. Київ, вул. Владимирська, 64/13.

E-mail: grishnova@ukr.net

Н.А. Азьмук,

канд. екон. наук, заместитель директора,Черкаський державний бізнес - коледж

Україна, 18028, м. Черкаси, вул. В. Чорновола 243

E-mail: azmukna@gmail.com

\section{РОЗВИТОК ЛЮДСЬКОГО КАПІТАЛУ І ТРАНСФОРМАЦІЯ ФОРМ ЗАЙНЯТОСТІ: ВЗАЕМОВПЛИВ І ВЗАЕМООБУМОВЛЕНІСТЬ}

У висококонкурентній глобалізаційній економіці людський капітал стає не тільки визначальним чинником конкурентоспроможності, а й домінуючою формою суспільного багатства, основою інтелектуального і соціального капіталу як умови не лише економічного, а й цивілізаційного прогресу в цілому.

Прямий взаємозв'язок між розвитком людського капіталу та трансформацією форм зайнятості виявляється в тому, що реалізується людський капітал на ринку праці через ті чи інші форми зайнятості, й ці форми тим складніші й різноманітніші, чим уникальніший людський капітал. Зворотний зв'язок проявляється в тому, що трансформація форм зайнятості надає додаткові можливості й висуває нові вимоги для накопичення людського капіталу, внаслідок чого відбувається його розвиток.

Принципові положення щодо особливостей використання людського капіталу в сучасних умовах полягають в такому: по-перше, розвиток людського капіталу залежить від інвестицій. Головним інвестором є сам працівник, який інвестує свої сили і час в нарощування свого людського капіталу і приймає рішення про доцільність та інтенсивність набуття нових знань, досвіду, саморозвитку в тій чи іншій сфері. При цьому чим вищий професійний, інтелектуальний рівень працівника, більші його можливості до продукування інновацій, тим вищий рівень його конкурентоспроможності. Це є одним із чинників, який зумовлює появу інноваційних форм людського капіталу.

По-друге, основним сектором використання людського капіталу в сучасній економіці є сфера послуг. Саме ця сфера економіки за своєю специфікою не вимагає значних матеріальних витрат і має значний потенціал для нарощування людського інтелектуального капіталу. Активний розвиток інформаційно-комп'ютерних технологій обумовлює потребу насамперед цього сектору економіки в інноваційних формах людського капіталу.

По-трєте, характерним для сучасних економічних систем є трансформація структури людського капіталу, а саме зниження частки специфічного людського капіталу. Це підвищує рівень мобільності працівників та зумовлює попит на тимчасову зайнятість. Основними факторами, що зумовлюють попит підприємств на тимчасових співробітників, є: зниження витрат, сезонні коливання попиту, можливість заміщення співробітників, швидка адаптація підприємства до економічних циклів, відсутність зобов'язань з гарантії зайнятості.

По-четверте, активний розвиток інформаційно-комп'ютерних технологій викликає переміщення певної кількості робочих місць поза офіси, що зумовлює появу нових форм організації робочих місць та активізацію розвитку інноваційних форм людського капіталу.

Інноваційні форми людського капіталу вимагають інноваційних форм його використання. Тому ситуація на сучасному ринку праці характеризується двома взаємопов'язаними тенденціями: по-перше, зміни у змісті праці зумовили попит серед працівників на нестандартну зайнятість, оскільки така форма дає більше свободи творчості і можливостей для самореалізації. 3 другого боку, сучасні підприємства активно шукають можливості для гнучкості та мобільності і тому зацікавлені у використанні гнучких форм зайнятості, насамперед дистанційної та тимчасової.

Ключові слова: людський капітал, інноваційні форми людського капіталу, нестандартні форми зайнятості, глобалізація, інформаційно-комп'ютерні технології. 


\section{O.A. Grishnova,}

Doctor of economic, professor, Taras Shevchenko National University of Kyiv,

Ukraine, 01601, city Kyiv, street Vladimirskiy, 64/13

E-mail: grishnova@ukr.net

N. A. Azmuk,

$\mathrm{PhD}$ in economic, deputy director State business-college

Ukraine, 18028, city Cherkasy, street V. Chernovola, 243

E-mail: azmukna@gmail.com

\section{DEVELOPMENT OF HUMAN CAPITAL AND TRANSFORMATION OF EMPLOYMENT FORMS: MUTUAL INFLUENCE AND INTERDEPENDENCE}

In a highly competitive and globalization economy human capital is not the only determinant of competitiveness, but also the dominant form of social wealth, the basis of intellectual and social capital as a condition for not only economic but also civilizational progress in general.

Direct relationship between human resources and transformation of forms of employment manifests in the realization of human capital in the labor market through some form of employment, and these forms are as complex and varied as human capital is unique. Feedback is shown in that the transformation of forms of employment provides additional opportunities and raises new challenges for human capital accumulation, resulting in its development.

The principal provisions for the use of the features of human capital in modern conditions are as follows: first, the development of human capital depends on investment. The main investor is the employee who invests their time and energy to build their human capital and decide on the appropriateness and intensity of acquiring new knowledge, experience, self-development in a particular area. Thus, the higher the professional and intellectual level of the employee, their ability to produce innovation, the higher the level of competitiveness. This is one of the factors that determines the appearance of innovative forms of human capital.

Second, the dominant sector of human capital use in today's economy is the service sector. This is the area of the economy that in its specificity requires considerable investments and has significant potential for increasing intellectual capital, especially human. Active development of ICT necessitates first of all the sector of innovative forms of human capital.

The third, characteristic of modern economies is the transformation of the structure of the human capital, namely the decrease in the proportion of specific human capital. This increases the mobility of workers and leads to the demand for temporary employment. The main factors that determine the demand for temporary employees of companies include: reducing costs, seasonal fluctuations in demand, the possibility of replacement staff, rapid adaptation of enterprises to economic cycles, lack of commitment to job security.

Fourth, the active development of information and computer technologies is moving some jobs out of the office, which leads to the emergence of new forms of employment and intensification of innovative forms of human capital.

Innovative forms of human capital require innovative forms of its use, because the situation in today's labor market is characterized by two related trends: first, changes in the content of labor demand caused among workers in non-standard employment as a form of giving more freedom of creativity and capacity for self-realization. On the other hand, modern enterprises are actively seeking opportunities for flexibility and mobility, and therefore interested in the use of flexible forms of employment, especially remote and temporary.

Keywords: human capital, innovative forms of the human capital, non-standard forms of employment, globalization, information-computer technologies. 